\title{
Six Sigma Single Sampling Variables Plan Indexed by Six Sigma AQL and Six Sigma AOQL
}

\author{
Dr. D. Senthilkumar \\ Department of Statistics, \\ PSG College of Arts \& Science, \\ Coimbatore -641014 .
}

\author{
B. Esha Raffie \\ Department of Statistics, \\ PSG College of Arts \& Science, \\ Coimbatore - 641014.
}

\begin{abstract}
In this paper, the procedure and tables for the selection of Six Sigma Single Sampling Variables Plan $\left(\operatorname{SSSSVP}_{\sigma} \mathrm{n}_{\sigma}\right.$, k)) indexed by Six Sigma AQL and Six Sigma AOQL. The properties of the Operating Characteristic (OC) with respect to the AOQ curve are studied. The comparison also made with existing plan.
\end{abstract}

\section{Keywords}

Single Sampling Plan, Six Sigma, Operating Characteristic curve, Average Outgoing Quality (AOQ), and Average Outgoing Quality Limit (AOQL).

\section{INTRODUCTION}

Variables sampling plan cover a major areas of acceptance sampling inspection, and often a single sampling plan is less complicated to use, when compared to other plans. Variable sampling plan is generally used when the characteristic of significance is measurable and normally distributed with mean $(\mu)$ and standard deviation $(\sigma)$. If one prefers to use a single sampling plan for variables under a rectification inspection scheme, the quality indicator for the selection of the sampling plan will be the average outgoing quality limit (AOQL). Rejected lots are often a nuisance to the producer as they result in extra work and cost. If too many lots are rejected, this will damage the reputation of the producer or supplier. From the producer point of view, he would prefer fixing an acceptable quality level (AQL) and designing sampling plan so that if the incoming product quality is maintained at AQL, most of his lot (say $99.9 \%$ ) will be accepted during the sampling inspection stage itself, inspection is necessary. Soundararajan (1981) has developed procedures and tables for the selection of single sampling plans for attributes for given AQL and AOQL. Govindaraju (1990) has developed procedures and tables for the selection of single sampling plans for variables indexed by AQL and AOQL. Govindaraju and Kuralmani (1991) have presented tables by using a computer program for determining single sampling plans for given AQL, Producer's risk and AOQL for the case of nonconforming units and nonconformities. Senthilkumar (2004) has developed procedures and tables for tightennormal -tighten variables sampling scheme indexed by
AQL and AOQL. Senthilkumar (2004) has extended this concept to Repetitive Group Variables Sampling Plan indexed by AQL and AOQL. Senthilkumar and Esha Raffie (2013) have studied six sigma single sampling variables plan and tables are constructed by using six sigma quality levels.

In this paper, tables and procedures for the selection of six sigma single sampling variables plan indexed by SSAQL and SSAOQL are given.

\section{Variable Sampling Plan and SSAOQL procedures}

For a variable sampling plan with sample size $\mathrm{n}_{\sigma}$ and acceptance constants $k_{\sigma}$, the probability of acceptance will be

$$
\begin{array}{ll} 
& \mathrm{P}_{\mathrm{a}}(\mathrm{p})=\mathrm{F}(\mathrm{w}) \\
\text { with } & \mathrm{w}=\left(\mathrm{v}-\mathrm{k}_{\sigma}\right) \sqrt{\mathrm{n}_{\sigma}}
\end{array}
$$

the fraction non-conforming in a given lot will be

with

$$
\begin{aligned}
& \mathrm{p}=\mathrm{F}(-\mathrm{v}) \\
& \mathrm{v}=(\mathrm{U}-\mu) / \sigma
\end{aligned}
$$

To determine the values of $n_{\sigma}$ and $k_{\sigma}$ the given values of $p_{1}$, $\mathrm{p}_{2}, \alpha$ and $\beta$ should satisfy the following equations. If the quality of the accepted lot is $\mathrm{p}$ and all defective units found in the rejected lots are replaced by non-defective units in a rectifying inspection plan, the Six Sigma Average Outgoing Quality (SSAOQ) can be approximated as

$$
\mathrm{SSAOQ}=\mathrm{p} \mathrm{P}_{\mathrm{a}}(\mathrm{p})
$$

where $\mathrm{P}_{\mathrm{a}}(\mathrm{p})$ is defined in equation (2. If $\mathrm{p}_{\mathrm{m}}$ is the proportion defective at which SSAOQ is maximum, one has

$$
\mathrm{SSAOQL}=\mathrm{p}_{\mathrm{m}} \mathrm{P}_{\mathrm{a}}\left(\mathrm{p}_{\mathrm{m}}\right)
$$

If SSAQL $\left(\mathrm{p}_{1}\right)$ is prescribed, then the corresponding value of $\mathrm{v}_{\mathrm{SSAQL}}$ or $\mathrm{v}_{1}$ will be fixed and if $\mathrm{P}_{\mathrm{a}}\left(\mathrm{p}_{1}\right)$ is fixed at $99.99966 \%$, that is $(1-\alpha)$. Where, $\alpha=$ $0.0000034 \times 10^{-6}$. Hence we have

$$
\mathrm{P}_{\mathrm{a}}\left(\mathrm{p}_{1}\right)=(1-\alpha)
$$


The value of $(1-\alpha)$ is 0.9999966 its normal table value is 4.499 that is,

$$
4.4999=\left(\mathrm{v}_{1}-\mathrm{k}_{\sigma}\right) \sqrt{\mathrm{n}_{\sigma}}
$$

So that for given SSAQL, $\mathrm{k}_{\sigma}$ is determined by the sample size $\mathrm{n}_{\sigma}$.

\subsection{Selection of known $\sigma$ SSSSVP for given SSAQL and SSAOQL}

The operating procedure of six sigma single sampling variables plan is described below:

Draw a random sample of size $n_{\sigma}$ inspect and record the measurement of the quality characteristic for each unit of the sample. Compute the sample mean $\bar{X}$, if $\bar{X}+k_{\sigma} \sigma \leq$ $\mathrm{U}$, or $\overline{\mathrm{X}}-\mathrm{k}_{\sigma} \sigma \geq \mathrm{L}$, the lot is accepted otherwise rejected. Table 1 is used for selection of $\sigma$ - method SSSSVP. For example, if the SSAQL is fixed at $\mathrm{p}_{1}=0.00005$ and the SSAOQL is fixed at $\mathrm{p}_{2}=0.00006$, Table 1 yields $\mathrm{n}_{\sigma}=2549$ and $\mathrm{k}_{\sigma}=3.801$, which is associated with 4.5 sigma level.

The user of Table 1 should understand the limitations of plans indexed by SSAOQL. Sampling with rectifying of rejected lots on the one hand reduces the average percentage of nonconforming items in the lots, but on the other hand introduces non-homogeneity in the series of lots finally accepted. That is, any particular lot will have a quality of $\mathrm{p} \%$ or $0 \%$ nonconforming depending on whether the lot is accepted or rectified. Thus the assumption underlying the SSAOQL principle is that the homogeneity in the qualities of individual lots is unimportant and only the average quality matters. For plans listed in Table 1 , if the individual lot quality happens to be the product quality $\mathrm{p}_{\mathrm{m}}$ at which SSAOQL occurs, then the associated probability of acceptance will be poor. Table 2 gives $\mathrm{P}_{\mathrm{a}}\left(\mathrm{p}_{\mathrm{m}}\right)$ values of plans given in Table 1. For example, for SSAQL of $\mathrm{p}_{1}=0.00001$ and SSAOQL of $\mathrm{p}_{2}=0.00003$, Table 2 gives $\mathrm{P}_{\mathrm{a}}\left(\mathrm{p}_{\mathrm{m}}\right)=0.80$. Then $\mathrm{p}_{\mathrm{m}}=\mathrm{SSAOQL} / \mathrm{P}_{\mathrm{a}}\left(\mathrm{p}_{\mathrm{m}}\right)=0.000037$. In order to avoid such inconvenience, the producer should maintain the process quality more or less at the SSAQL. The high rate of rejection of lots at $\mathrm{p}=\mathrm{p}_{\mathrm{m}}$ will also indirectly put pressure on the producer to improve the submitted quality.

\subsection{Selection of unknown $\sigma$ SSSSVP for given SSAQL and SSLQL}

If the population standard deviation $\sigma$ is unknown, then it is estimated from the sample standard deviation S (n-1 in the division). If the sample sizes of the unknown sigma variables plan (S-method) is $n_{s}$ and the acceptance constant is $\mathrm{k}_{\mathrm{s}}$, then the operating procedure is

Draw a random sample of size $\mathrm{n}_{\sigma}$ inspect and record the measurement of the quality characteristic for each unit of the sample. Compute the sample mean $\bar{X}$, if $\bar{X}+k_{s} S \geq$ $\mathrm{L}$, or $\quad \overline{\mathrm{X}}-\mathrm{k}_{\mathrm{s}} \mathrm{S} \geq \mathrm{L}$, the lot is accepted otherwise rejected. Where, $\mathrm{S}=\left[\sum\left(\mathrm{x}_{\mathrm{i}}-\overline{\mathrm{X}}\right)^{2} /(\mathrm{n}-1)\right]^{1 / 2}$

Then, for given SSAQL and SSAOQL, an S-method plan can be found from the $\sigma$-method plan using the above formulae. Table 1 also gives such matched s-method plan. For example, for given SSAQL of $\mathrm{p}_{1}=0.00004$ and SSAOQL of $\mathrm{p}_{2}=0.00006$, one obtains the parameters of the S-method plan from Table 1 to be $\mathrm{n}_{\mathrm{s}}=5509$ and $\mathrm{k}_{\mathrm{s}}=3.772$, which is associated with 4.7 sigma level.

\subsection{Comparing SSVP (AQL, AOQL) with SSSSVP (AQL, AOQL)}

When $\mathrm{AQL}=0.0004$ and $\mathrm{AOQL}=0.0005$ using Table 1 of Govindaraju (1990) one can locate the values of $n=47$ and $\mathrm{k}=3.113$. This study give values of $\mathrm{SSAQL}=0.0004$ and $\mathrm{SSAOQL}=0.0005$ using Table 1 one can locate the values of $n=1291, k=3.228$ and $\sigma$-level associated with 4.3.

It is to be noted that the sample size of the variables scheme (SSSSVP (AQL, AOQL)) is too larger than that of the SSVP (AQL, AOQL) and acceptance constant of SSSSVP is just near of SSVP.

\subsection{Plotting $O C$ and $A O Q$ curves}

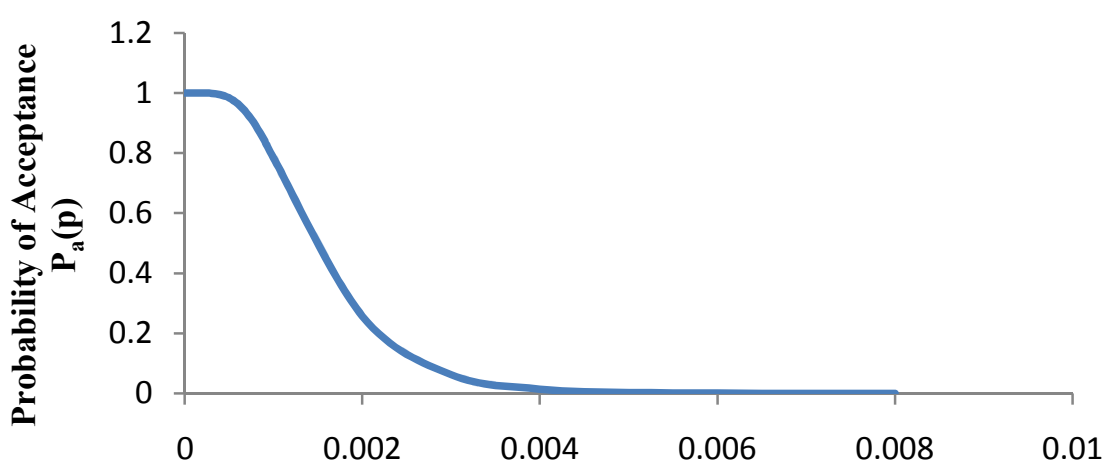

Fraction Defective (p)

Figure 1: SSSSVP (AQL, AOQL) OC curves with $\mathrm{n}=1729$ and $\mathrm{k}=3.836$ respectively. 
From this figure 1, it shows percentage-fraction defectives along the horizontal ('X'), axis and probability of acceptance along the vertical ('Y') axis. Lots having more than the acceptable percentage of defectives are rejected. It can be observed that, for good quality, i.e. for smaller value of the fraction defective.

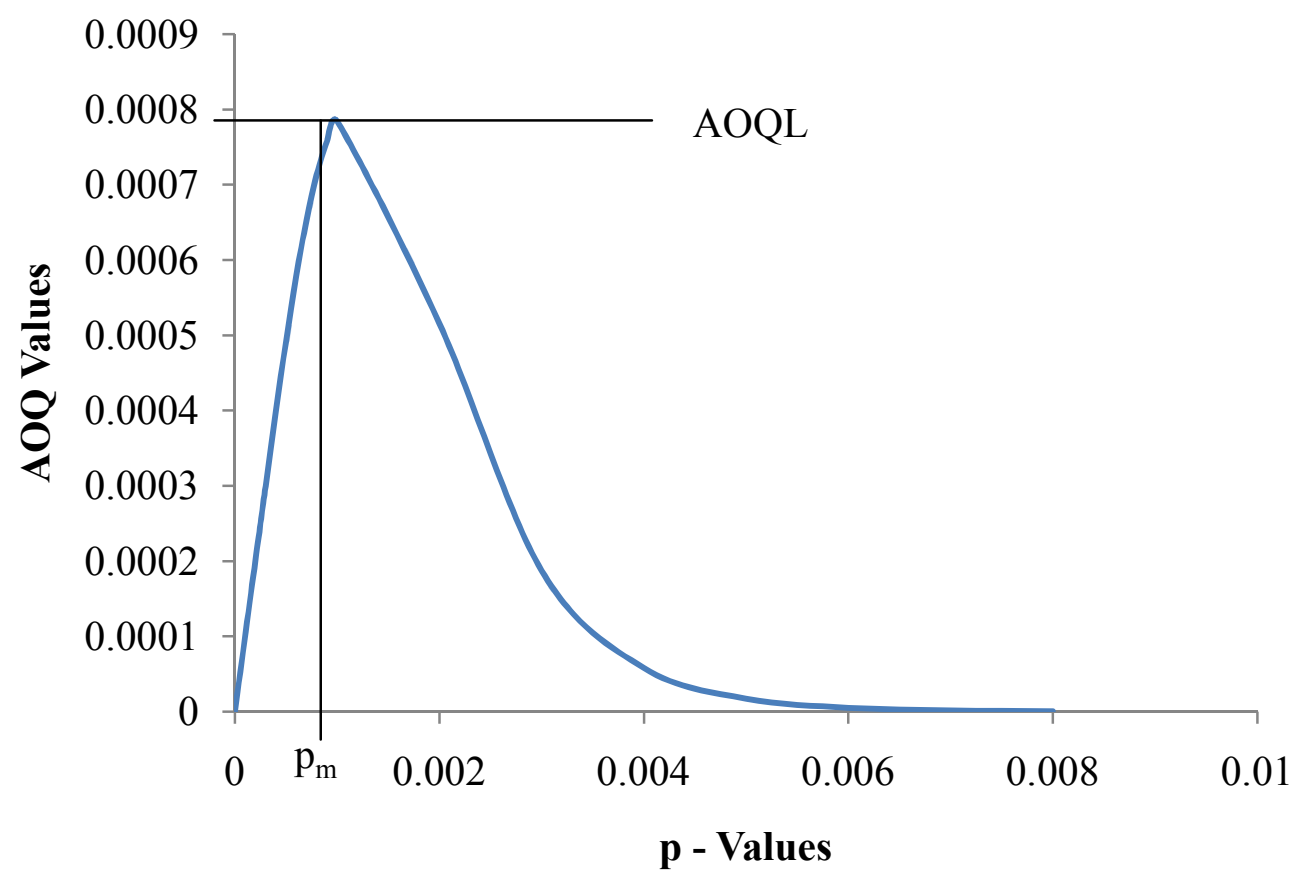

Figure 2: SSSSVP of AOQ Curve with $n=1729$ and $k=3.836$ respectively

From this figure 2, an inspection station has been installed between two production processes. The production process, when operating correctly, has an acceptable quality level of 0.1 percent. The consuming process, which is expensive, has a specified lot tolerance proportion defective of 0.08 percent. The production process produces in batch sizes; if

\section{Construction of Table 1 and 2}

For constructing Table 1, a trial value of $\mathrm{p}_{\mathrm{m}}$ is assumed and the probability of acceptance at $p_{m}$ is found from (4) as

$$
\mathrm{P}_{\mathrm{a}}\left(\mathrm{p}_{\mathrm{m}}\right)=\mathrm{AOQL} / \mathrm{p}_{\mathrm{m}}
$$

The auxiliary variables $\mathrm{v}_{\mathrm{m}}$ and $\mathrm{w}_{\mathrm{m}}$ corresponding to the values of $\mathrm{p}_{\mathrm{m}}$ and $\mathrm{P}_{\mathrm{a}}\left(\mathrm{p}_{\mathrm{m}}\right)$ respectively, are found using (1) and (2). For given $\mathrm{p}_{1}$ values of $\mathrm{v}_{1}$ and $\mathrm{w}_{1}=4.4999$ are known. With the values of $\mathrm{v}_{1}, \mathrm{w}_{1}, \mathrm{v}_{\mathrm{m}}$ and $\mathrm{w}_{\mathrm{m}}$, the following equation is used for calculating $n_{\sigma}$

$$
\mathrm{n}_{\sigma}=\left(\mathrm{w}_{1}-\mathrm{w}_{\mathrm{m}}\right)^{2} /\left(\mathrm{v}_{1}-\mathrm{v}_{\mathrm{m}}\right)^{2}
$$

Equation (7) is the formula for finding the sample size of a known $\sigma$ Six Sigma Single Sampling Plan for two points given on the OC curve it is checked whether the assumed value of $\mathrm{p}_{\mathrm{m}}$ corresponds to the proportions non-conforming at which the SSAOQL occurs or not. That is, it is checked

whether or not the trial value of $\mathrm{p}_{\mathrm{m}}$ satisfies the following equation a batch is rejected by the inspector, the entire batch must be checked and the defective items reworked. Consequently, management wants no more than a 0.00034 percent producer's risk and, because of the expensive process that follows, no more than a 0.00068 percent chance of accepting a lot with 0.08 percent defectives or worse.

$$
\text { A O Q L } \left.\left.-p_{m}^{2} \sqrt{n_{\sigma}\left(\operatorname { e x p } \left[-\left(v_{m}^{2}\right.\right.\right.}-w_{m}^{2}\right)\right]=0
$$

The equation (8) was obtained from the following relation

$$
\frac{d\left(S_{A O Q}\right)}{d p}=P_{a}(p)+p \frac{d P_{a}(p)}{d p}=0
$$

In which

$$
\left.\left.\frac{\mathrm{dP}_{\mathrm{a}}(\mathrm{P})}{\mathrm{dp}}=-\sqrt{\mathrm{n}_{\sigma}\left(\operatorname { e x p } \left[-\left(\mathrm{v}_{\mathrm{m}}^{2}\right.\right.\right.}-\mathrm{w}_{\mathrm{m}}^{2}\right)\right]
$$

If assumed value of $p_{m}$ does not satisfy (9), then another trial value of $p_{m}$ is obtained from (9) by numerical methods. The methods of successive substitution is often found to give good results and (9) is rewritten for this purpose as

$$
\mathrm{p}_{\mathrm{m}}=\frac{\mathrm{AOQL}}{\left.\left.\mathrm{p}_{\mathrm{m}} \sqrt{\mathrm{n}_{\sigma}\left(\operatorname { e x p } \left[-\left(\mathrm{v}_{\mathrm{m}}^{2}\right.\right.\right.}-\mathrm{w}_{\mathrm{m}}^{2}\right)\right]}
$$

After determining the next trial value of $p_{m}$, again the values of $\mathrm{v}_{\mathrm{m}}, \mathrm{w}_{\mathrm{m}}$, and $\mathrm{n}_{\sigma}$ are found and the condition (8) rechecked. This iterative procedure continues until the convergence of $\mathrm{p}_{\mathrm{m}}$ is achieved. Then the value of $\mathrm{k}_{\sigma}$ is obtained from (5). For obtaining the values of $\mathrm{v}_{1}, \mathrm{w}_{1}$ and 
$\mathrm{w}_{\mathrm{m}}$, the approximation for the ordinate of the cumulative normal distribution available in Abramowitz and Stegun (1972) was used. A procedure for finding parameters of Smethod scheme from $\sigma$ - method scheme with parameters $\left(\mathrm{n}_{\mathrm{s}} ; \mathrm{k}_{\mathrm{s}}\right)$ were derived using Hamaker (1979) approximation as follows:

$$
\begin{gathered}
\mathrm{n}_{\mathrm{s}}=\mathrm{n}_{\sigma}\left(1+\mathrm{k}_{\sigma}^{2} / 2\right), \\
\mathrm{k}_{\mathrm{s}}=\mathrm{k}_{\sigma}(4 \mathrm{n}-4) /(4 \mathrm{n}-5)
\end{gathered}
$$

The $\sigma$-method plans were obtained using computer search routine through $\mathrm{C}++$ programme. Table 1 provides the values of $\mathrm{n}_{\sigma}, \mathrm{k}_{\mathrm{T} \sigma}, \mathrm{k}_{\mathrm{N} \sigma}, \mathrm{n}_{\mathrm{s}}, \mathrm{k}_{\mathrm{Ts}}$ and $\mathrm{k}_{\mathrm{Ns}}$ which satisfy the equation (5), (12) and (13). For selected combinations of SSAQL and SSAOQL, Table 1 and 2 were constructed by using the iterative procedure through computer programme.

\section{Conclusion}

In this article in attempt is made to design SSSSVP which has the quality of acceptance $1-3.4 \times 10^{-6}$ in the long run. This plan will help the industrial shop floor Engineers, to use total quality control practices, of which the sampling inspection plan is an approach used for manufacturing products. Tables are provided here which tailor-made, handy and ready-made use to the industrial shop-floor condition. If quality levels SSAQL and SSAOQL are known, these plans are most suitable for industries but are applying Six Sigma initiative in their organization.

\section{REFERENCES}

1 Abramowitz, M. and Stegun, I.A. (1972): Handbook of Mathematical functions, Dover Publications, New York, NY

2 Dodge, H.F. and Romig, H.G. (1942): Army service forces tables, Bell telephone laboratories, United States.
3 Govindaraju, K. (1990): Single sampling Plans for Variables Indexed by AQL and AOQL, Journal of Quality Technology, Vol.22, No.4, pp.310-313.

4 Govindaraju, K. and Kuralmani, V. (1991): Determination of single sampling attributes plans for given (AQL, AOQL), Communications in statistics. Simulation and Computation, Vol.20, No.2, pp 529538.

5 Hamaker, H.C. (1979): Acceptance Sampling for Percent Defective and by Attributes, Journal of Quality Technology, Vol.11, pp.138-148.

6 Senthilkumar, D. (2004): Tighten - Normal - Tighten variables sampling scheme indexed by AQL and AOQL, "National seminar on frontiers in applied statistics and computer applications", Department of Statistics, Bharathiar university, Coimbatore, Tamil Nadu, January 29 -30.

7 Senthilkumar, D. (2004): Repetitive Group Sampling variables inspection plan indexed by $A Q L$ and AOQL, "National seminar on "Recent Advances in Statistical and Methodologies and Applications", Department of Statistics, Bharathiar University, Coimbatore, Tamil Nadu, March 18 -19.

8 Senthilkumar, D. and Esha Raffie, B. "Designing Six Sigma Single Sampling Variables Plan Indexed By Six Sigma Quality Levels", International Journal of Advanced Engineering Sciences and Technologies, Vol. 12, Issue No. 2. pp. 001-009, 2013.

9 Soundararajan, V. (1981): Single Sampling Attributes Plans Indexed by AQL and AOQL, Journal of Quality Technology, Vol.13, No.3, pp 195-200. 
Six Sigma Single Sampling Variables Plan Indexed by Six Sigma AQL and Six Sigma AOQL

Table 1: SSSSVP(n, $k, \sigma$ - level) with known and unkunown $\sigma$ indexed by SSAQL and SSAOQL

\begin{tabular}{|c|c|c|c|c|c|c|c|}
\hline $\begin{array}{c}\text { SSAQL } \\
(\%)\end{array}$ & $\begin{array}{c}\text { SSAOQL } \\
(\%)\end{array}$ & $\mathbf{n}_{\boldsymbol{\sigma}}$ & $\mathbf{k}_{\boldsymbol{\sigma}}$ & $\sigma-$ Level & $\mathbf{n}_{\mathbf{s}}$ & $\mathbf{k}_{\mathbf{s}}$ & $\sigma-$ Level \\
\hline \multirow{10}{*}{0.001} & 0.002 & 306 & 4.008 & 3.7 & 2764 & 4.008 & 4.5 \\
\hline & 0.003 & 144 & 3.889 & 3.4 & 1233 & 3.890 & 4.2 \\
\hline & 0.004 & 96 & 3.806 & 3.3 & 791 & 3.807 & 4.1 \\
\hline & 0.005 & 74 & 3.742 & 3.1 & 592 & 3.744 & 4.0 \\
\hline & 0.006 & 62 & 3.691 & 3.1 & 484 & 3.693 & 3.9 \\
\hline & 0.007 & 53 & 3.648 & 3.0 & 406 & 3.650 & 3.9 \\
\hline & 0.008 & 47 & 3.610 & 9 & 353 & 3.613 & 3.8 \\
\hline & 0.009 & 43 & 3.577 & 9 & 318 & 3.580 & 3.8 \\
\hline & 0.01 & 39 & 3.548 & 8 & 284 & 3.551 & 3.7 \\
\hline & 0.02 & 24 & 3.354 & 6 & 159 & 3.359 & 3.5 \\
\hline \multirow{10}{*}{0.002} & 0.003 & 670 & 3.933 & 4.0 & 5852 & 3.933 & 4.7 \\
\hline & 0.004 & 294 & 3.845 & 3.7 & 2467 & 3.845 & 4.5 \\
\hline & 0.005 & 183 & 3.774 & 3.5 & 1486 & 3.775 & 4.3 \\
\hline & 0.006 & 134 & 3.718 & 3.4 & 1060 & 3.719 & 4.2 \\
\hline & 0.007 & 107 & 3.671 & 3.3 & 828 & 3.672 & 4.1 \\
\hline & 0.008 & 89 & 3.631 & 3.2 & 676 & 3.632 & 4.1 \\
\hline & 0.009 & 77 & 3.356 & 3.2 & 511 & 3.358 & 4.0 \\
\hline & 0.01 & 69 & 3.565 & 3.1 & 507 & 3.567 & 4.0 \\
\hline & 0.02 & 36 & 3.612 & 8 & 271 & 3.615 & 3.7 \\
\hline & 0.03 & 27 & 3.324 & 7 & 176 & 3.329 & 3.6 \\
\hline \multirow{10}{*}{0.003} & 0.004 & 1249 & 3.885 & 4.2 & 10675 & 3.885 & 4.9 \\
\hline & 0.005 & 448 & 3.800 & 3.9 & 3683 & 3.800 & 4.6 \\
\hline & 0.006 & 281 & 3.744 & 3.7 & 2250 & 3.744 & 4.4 \\
\hline & 0.007 & 199 & 3.694 & 3.6 & 1557 & 3.695 & 4.3 \\
\hline & 0.008 & 155 & 3.651 & 3.5 & 1188 & 3.652 & 4.2 \\
\hline & 0.009 & 127 & 3.615 & 3.4 & 957 & 3.616 & 4.2 \\
\hline & 0.01 & 109 & 3.582 & 3.3 & 808 & 3.583 & 4.1 \\
\hline & 0.02 & 49 & 3.371 & 3.0 & 327 & 3.374 & 3.8 \\
\hline & 0.03 & 35 & 3.248 & 8 & 220 & 3.252 & 3.7 \\
\hline & 0.04 & 28 & 3.161 & 7 & 168 & 3.166 & 3.6 \\
\hline \multirow{6}{*}{0.004} & 0.005 & 1729 & 3.836 & 4.3 & 14450 & 3.836 & 5.0 \\
\hline & 0.006 & 679 & 3.772 & 4.0 & 5509 & 3.772 & 4.7 \\
\hline & 0.007 & 393 & 3.717 & 3.8 & 3108 & 3.717 & 4.5 \\
\hline & 0.008 & 271 & 3.671 & 3.7 & 2097 & 3.671 & 4.4 \\
\hline & 0.009 & 208 & 3.632 & 3.6 & 1580 & 3.633 & 4.3 \\
\hline & 0.01 & 169 & 3.598 & 3.5 & 1263 & 3.599 & 4.3 \\
\hline
\end{tabular}


Table 1 (continued...)

\begin{tabular}{|c|c|c|c|c|c|c|c|}
\hline $\begin{array}{c}\text { SSAQL } \\
(\%)\end{array}$ & $\begin{array}{c}\text { SSAOQL } \\
(\%)\end{array}$ & $\mathbf{n}_{\boldsymbol{\sigma}}$ & $\mathbf{k}_{\boldsymbol{\sigma}}$ & $\sigma$ - Level & $\mathbf{n}_{\mathbf{s}}$ & $\mathbf{k}_{\mathbf{s}}$ & $\sigma-$ Level \\
\hline \multirow{4}{*}{0.004} & 0.02 & 63 & 3.379 & 3.1 & 423 & 3.381 & 3.9 \\
\hline & 0.03 & 43 & 3.254 & 9 & 271 & 3.257 & 3.8 \\
\hline & 0.04 & 33 & 3.165 & 8 & 198 & 3.169 & 3.6 \\
\hline & 0.05 & 28 & 3.096 & 7 & 162 & 3.101 & 3.6 \\
\hline \multirow{9}{*}{0.005} & 0.006 & 2549 & 3.801 & 4.5 & 20962 & 3.801 & 5.1 \\
\hline & 0.007 & 904 & 3.741 & 4.1 & 7230 & 3.741 & 4.8 \\
\hline & 0.008 & 515 & 3.692 & 3.9 & 4025 & 3.692 & 4.6 \\
\hline & 0.009 & 336 & 3.645 & 3.8 & 2568 & 3.645 & 4.5 \\
\hline & 0.01 & 266 & 3.615 & 3.7 & 2004 & 3.615 & 4.4 \\
\hline & 0.02 & 80 & 3.388 & 3.2 & 539 & 3.390 & 4.0 \\
\hline & 0.03 & 51 & 3.260 & 3.0 & 322 & 3.263 & 3.8 \\
\hline & 0.04 & 39 & 3.169 & 9 & 235 & 3.172 & 3.7 \\
\hline & 0.05 & 33 & 3.099 & 8 & 191 & 3.103 & 3.6 \\
\hline \multirow{8}{*}{0.006} & 0.007 & 3310 & 3.768 & 4.6 & 26807 & 3.768 & 5.1 \\
\hline & 0.008 & 1156 & 3.714 & 4.2 & 9129 & 3.714 & 4.8 \\
\hline & 0.009 & 648 & 3.669 & 4.0 & 5010 & 3.669 & 4.7 \\
\hline & 0.01 & 437 & 3.631 & 3.9 & 3318 & 3.631 & 4.6 \\
\hline & 0.02 & 100 & 3.391 & 3.3 & 675 & 3.392 & 4.1 \\
\hline & 0.03 & 60 & 3.266 & 3.1 & 380 & 3.268 & 3.9 \\
\hline & 0.04 & 45 & 3.175 & 3.0 & 272 & 3.178 & 3.8 \\
\hline & 0.05 & 37 & 3.104 & 9 & 215 & 3.108 & 3.7 \\
\hline \multirow{7}{*}{0.007} & 0.008 & 4139 & 3.738 & 4.6 & 33055 & 3.738 & 5.2 \\
\hline & 0.009 & 1428 & 3.689 & 4.3 & 11145 & 3.689 & 4.9 \\
\hline & 0.01 & 780 & 3.647 & 4.1 & 5967 & 3.647 & 4.7 \\
\hline & 0.02 & 125 & 3.410 & 3.4 & 852 & 3.411 & 4.2 \\
\hline & 0.03 & 71 & 3.273 & 3.2 & 451 & 3.275 & 3.9 \\
\hline & 0.04 & 51 & 3.179 & 3.0 & 309 & 3.182 & 3.8 \\
\hline & 0.05 & 42 & 3.108 & 9 & 245 & 3.111 & 3.7 \\
\hline \multirow{6}{*}{0.008} & 0.009 & 4696 & 3.709 & 4.7 & 36997 & 3.709 & 5.2 \\
\hline & 0.01 & 1559 & 3.662 & 4.3 & 12012 & 3.662 & 4.9 \\
\hline & 0.02 & 155 & 3.410 & 3.5 & 1056 & 3.411 & 4.2 \\
\hline & 0.03 & 82 & 3.279 & 3.3 & 523 & 3.281 & 4.0 \\
\hline & 0.04 & 58 & 3.184 & 3.1 & 352 & 3.186 & 3.9 \\
\hline & 0.05 & 46 & 3.112 & 3.0 & 269 & 3.115 & 3.8 \\
\hline
\end{tabular}


Six Sigma Single Sampling Variables Plan Indexed by Six Sigma AQL and Six Sigma AOQL

Table 1 (continued...)

\begin{tabular}{|c|c|c|c|c|c|c|c|}
\hline $\begin{array}{c}\text { SSAQL } \\
(\%)\end{array}$ & $\begin{array}{c}\text { SSAOQL } \\
\mathbf{( \% )}\end{array}$ & $\mathbf{n}_{\boldsymbol{\sigma}}$ & $\mathbf{k}_{\boldsymbol{\sigma}}$ & $\boldsymbol{\sigma}-$ Level & $\mathbf{n}_{\mathbf{s}}$ & $\mathbf{k}_{\mathbf{s}}$ & $\boldsymbol{\sigma}-$ Level \\
\hline \multirow{4}{*}{0.009} & 0.01 & 3899 & 3.673 & 4.6 & 30200 & 3.673 & 5.2 \\
\cline { 2 - 8 } & 0.02 & 193 & 3.422 & 3.6 & 1323 & 3.423 & 4.3 \\
\cline { 2 - 8 } & 0.03 & 95 & 3.285 & 3.3 & 608 & 3.286 & 4.0 \\
\cline { 2 - 8 } & 0.04 & 65 & 3.189 & 3.2 & 396 & 3.191 & 3.9 \\
\hline \multirow{3}{*}{0.01} & 0.05 & 51 & 3.115 & 3.0 & 298 & 3.118 & 3.8 \\
\cline { 2 - 8 } & 0.02 & 245 & 3.431 & 3.7 & 1687 & 3.432 & 4.4 \\
\cline { 2 - 8 } & 0.03 & 110 & 3.290 & 3.4 & 705 & 3.291 & 4.1 \\
\hline \multirow{3}{*}{0.02} & 0.04 & 73 & 3.194 & 3.2 & 445 & 3.196 & 3.9 \\
\cline { 2 - 8 } & 0.03 & 554 & 3.349 & 4.0 & 3661 & 3.349 & 4.6 \\
\hline \multirow{2}{*}{0.03} & 0.05 & 221 & 3.237 & 3.7 & 1379 & 3.238 & 4.3 \\
\cline { 2 - 8 } & 0.04 & 941 & 3.285 & 4.2 & 6018 & 3.285 & 4.8 \\
\hline 0.04 & 0.05 & 1291 & 3.228 & 4.3 & 8017 & 3.228 & 4.9 \\
\hline
\end{tabular}

Table 2: $P_{a}\left(p_{m}\right)$ Values of known $\sigma$ plans

\begin{tabular}{|c|c|c|c|c|c|c|c|c|c|c|c|c|c|}
\hline \multirow{2}{*}{$\begin{array}{c}\text { SSAOQL } \\
(\%)\end{array}$} & \multicolumn{10}{|c|}{ SSAQL (\%) } \\
\hline & 0.001 & 0.002 & 0.003 & 0.004 & 0.005 & 0.006 & 0.007 & 0.008 & 0.009 & 0.01 & 0.02 & 0.03 & 0.04 \\
\hline 0.002 & 0.80 & & & & & & & & & & & & \\
\hline 0.003 & 0.80 & 0.97 & & & & & & & & & & & \\
\hline 0.004 & 0.75 & 0.87 & 0.95 & & & & & & & & & & \\
\hline 0.005 & 0.72 & 0.84 & 0.91 & 0.98 & & & & & & & & & \\
\hline 0.006 & 0.69 & 0.80 & 0.89 & 0.92 & 0.97 & & & & & & & & \\
\hline 0.007 & 0.66 & 0.78 & 0.82 & 0.90 & 0.95 & 0.97 & & & & & & & \\
\hline 0.008 & 0.65 & 0.75 & 0.85 & 0.89 & 0.94 & 0.95 & 0.98 & & & & & & \\
\hline 0.009 & 0.63 & 0.74 & 0.80 & 0.87 & 0.91 & 0.93 & 0.95 & 0.99 & & & & & \\
\hline 0.01 & 0.62 & 0.72 & 0.78 & 0.83 & 0.87 & 0.91 & 0.91 & 0.91 & 0.91 & & & & \\
\hline 0.02 & 0.54 & 0.62 & 0.68 & 0.72 & 0.76 & 0.79 & 0.81 & 0.83 & 0.84 & 0.93 & & & \\
\hline 0.03 & & 0.58 & 0.63 & 0.66 & 0.70 & 0.72 & 0.75 & 0.77 & 0.79 & 0.80 & 0.94 & & \\
\hline 0.04 & & & 0.59 & 0.63 & 0.66 & 0.68 & 0.70 & 0.72 & 74.00 & 0.76 & 0.84 & 0.95 & \\
\hline 0.05 & & & & 0.59 & 0.63 & 0.65 & 0.67 & 0.69 & 0.71 & 0.72 & 0.84 & 0.91 & 0.98 \\
\hline
\end{tabular}

